\title{
Tourist Viewshed Externalities and Wind Energy Production
}

\author{
Jacob R. Fooks, Kent D. Messer, Joshua M. Duke, \\ Janet B. Johnson, Tongzhe Li, and George R. Parsons
}

\begin{abstract}
This study uses an experiment where ferry passengers are sold hotel room "views" to evaluate the impact of wind turbines views on tourists' vacation experience. Participants purchase a chance for a weekend hotel stay. Information about the hotel rooms was limited to the quality of the hotel and its distance from a large wind turbine, as well as whether or not a particular room would have a view of the turbine. While there was generally a negative effect of turbine views, this did not hold across all participants, and did not seem to be effected by distance or hotel quality.
\end{abstract}

Key Words: field experiment, tourism, visual disamenities, wind turbines

While wind energy is a promising source of renewable energy, it continues to make up a small fraction of the world's energy supply (Hau 2005, Kumar et al. 2016). Placement of wind turbines has prompted public concerns related to their effects on wildlife and scenic views (U.S. Department of Energy (U.S. DOE) 2015, for a review, see Ladenburg 2009). This has been especially relevant in coastal areas, where the proposed development of large offshore wind energy facilities in states including Massachusetts, New Jersey, Delaware, Virginia, and Oregon have been seen as a potential threat to the tourism industry. The response from the tourism industry has delayed or even blocked development of offshore wind facilities in some of these states. Literature surrounding economic effects on residents of wind turbines has mostly focused on residential property values through hedonic value studies focusing on the relationship between property price and turbine density (Sterzinger, Beck, and Kostiuk 2003, Poletti 2005, Heintzelman and Tuttle 2012, Lang, Opaluch, and Sfinarolakis 2014, Gibbons 2015). The values of beach community residents, however, may be different from the values of tourists visiting those communities. Other research has used stated-preference

Jacob R. Fooks, USDA Economic Research Service; Kent D. Messer, Joshua M. Duke, Janet B. Johnson, and George R. Parsons, University of Delaware; Tongzhe Li, Department of Economics, University of Windsor, Windsor, Canada. Correspondence: Jacob R. Fooks - 1101 Connecticut Ave NW \#750, Washington, DC 20036 - phone: 202-694-5068 - Email: jacob.fooks@ers.usda.gov

The data for this research were collected when Fooks was at the University of Delaware. This work was supported by NSF EPSCoR ID\#0814251. The views expressed here are those of the authors and may not be attributed to the Economic Research Service or the U.S. Department of Agriculture.

Agricultural and Resource Economics Review 46/2 (August 2017) 224-241

(C) USDA ERS 2017. This is a work of the U.S. Government and is not subject to copyright protection in the United States. Outside of the United States, this is an Open Access article, distributed under the terms of the Creative Commons Attribution licence (http://creativecommons.org/licenses/by/ 4.0/), which permits unrestricted re-use, distribution, and reproduction in any medium, provided the original work is properly cited. 
methods to measure preferences for reduction in the effects of offshore wind turbines (Gee 2010, Krueger, Parsons, and Firestone 2011, Landry et al. 2012, Parsons et al. 2016), or preferences for offshore turbines relative to other renewables (Ladenburg 2014). Recently, researchers have started to use choice experiments to access how wind farms influence individual preferences (Lutzeyer, Phaneuf, and Taylor 2016). This study uses an economic field experiment using actual beach visitors as research participants.

Participants were offered an opportunity to bid on chances to win hotel rooms in a beach resort town. Participants bid on rooms of differing quality and location. We worked with private hotel owners to offer rooms in our experiment as either having wind turbine views or not. This allowed us to obtain a measure of beach visitors' preferences for otherwise identical rooms, varying only the existence of wind turbine views from the room.

We find a negative effect of turbine views on beach visitors' willingness to pay for hotel rooms, however this effect does not hold for all visitors. Indeed, a small portion of the sample were willing to pay a premium for turbine views. We were unable to find any evidence that these values varied either with distance or hotel quality.

\section{Methods}

This research uses a within-subject field experiment offering participants the opportunity to purchase a lottery for a weekend stay at one of several hotels in Lewes, Delaware, a popular coastal vacation community. Lewes has a large wind turbine that is visible from nearby hotels. This experiment estimated willingness to pay (WTP) for hotel rooms as a function of distance from the wind turbine and hotel quality measured by a common star rating. Specifically, WTP for the view of the wind turbine was isolated by offering rooms that were distinguished only by the presence or absence of a wind turbine view from the room. The question of interest is whether there is a significant WTP a premium or not for rooms without turbine views, and, for rooms with turbine views, if WTP is affected by the quality of the hotel or the distance from the turbine. Table 1 describes the full set of hypotheses.

This experiment used the BDM mechanism (Becker, DeGroot, and Marschak 1964) to offer lotteries for six different hotel rooms. This mechanism is a type of auction commonly used in economic experiments to obtain a theoretically consistent measurement of participant value for an item by soliciting bids then randomly selecting a price. Bids below the price do not purchase the item; bids above the price purchase the item at the randomly selected price. The experiment was conducted during the summer on a ferry on the Lewes-Cape May Ferry traveling between the coastal vacation towns of Lewes, Delaware, and Cape May, New Jersey. A one-way ferry trip lasted about 85 minutes. This sample population was selected for two reasons. First, ferry riders, at least on this particular ferry during the busiest summer weekends, are largely vacationers to either the Delaware beaches or southern 


\section{Table 1. Hypotheses and Results}

\begin{tabular}{|c|c|c|c|c|}
\hline & Hypothesis & Statement & Result & Description \\
\hline 1 & $\begin{array}{l}\text { WTP is the same for hotel rooms regardless of distance to } \\
\text { a turbine. }\end{array}$ & $\begin{array}{l}\mathrm{H}_{0}: \beta_{\text {Near }}=0 \\
\mathrm{H}_{1}: \beta_{\text {Near }} \neq 0\end{array}$ & $\begin{array}{l}\text { Reject } \\
\mathrm{p}=0.005\end{array}$ & $\begin{array}{l}\text { WTP is less for hotel rooms closer to } \\
\text { a turbine. }\end{array}$ \\
\hline 2 & $\begin{array}{l}\text { WTP is the same for hotel rooms with or without turbine } \\
\text { views. }\end{array}$ & $\begin{array}{l}\mathrm{H}_{0}: \beta_{\text {Turbine }}=0 \\
\mathrm{H}_{1}: \beta_{\text {Turbine }} \neq 0\end{array}$ & $\begin{array}{l}\text { Reject } \\
\mathrm{p}=0.008\end{array}$ & $\begin{array}{l}\text { WTP is less for hotel rooms with } \\
\text { turbine views. }\end{array}$ \\
\hline 3 & WTP is same for hotels with different star rating. & $\begin{array}{l}\mathrm{H}_{0}: \beta_{\text {Three-star }}=0 \\
\mathrm{H}_{1}: \beta_{\text {Turbine }} \neq 0\end{array}$ & $\begin{array}{l}\text { Reject } \\
\mathrm{p}=0.000\end{array}$ & $\begin{array}{l}\text { WTP is more for three-star hotel } \\
\text { than } \\
\text { a one-star hotel. }\end{array}$ \\
\hline 4 & $\begin{array}{l}\text { WTP for rooms with turbine views does not vary with } \\
\text { distance up to } 1.5 \text { miles. }\end{array}$ & $\begin{array}{l}\mathrm{H}_{0}: \beta_{\text {TurbXNear }}=0 \\
\mathrm{H}_{1}: \beta_{\text {TurbXNear }} \neq 0\end{array}$ & $\begin{array}{l}\text { Fail to reject } \\
\mathrm{p}=0.897\end{array}$ & $\begin{array}{l}\text { No significant difference in WTP for } \\
\text { turbine views was detected. }\end{array}$ \\
\hline 5 & $\begin{array}{l}\text { WTP for rooms with turbine views does not vary by the } \\
\text { hotel's quality. }\end{array}$ & $\begin{array}{l}\mathrm{H}_{0}: \beta_{\text {TurbX3Star }}=0 \\
\mathrm{H}_{1}: \beta_{\text {TurbX3Star }} \neq 0\end{array}$ & $\begin{array}{l}\text { Fail to reject } \\
\mathrm{p}=0.496\end{array}$ & $\begin{array}{l}\text { WTP for turbine views is not } \\
\text { influenced by the hotel's quality. }\end{array}$ \\
\hline
\end{tabular}

(1)

1 WTP is the same for hotel rooms regardless of distance to TP is the same for hotel rooms with or without turbine a turbine.

$\mathrm{H}_{0}: \beta_{\text {Turbine }}=0 \quad$ Reject

$\mathrm{H}_{1}: \beta_{\text {Turbine }} \neq 0 \quad \mathrm{p}=0.008$

$\mathrm{H}_{0}: \beta_{\text {Three-star }}=0 \quad$ Reject

$\mathrm{H}_{1}: \beta_{\text {Turbine }} \neq 0 \quad \mathrm{p}=0.000$ than

a one-star hotel. 
New Jersey shores. Second, this group offers a captive sample for a period long enough to run a fairly complicated design. In other locations, finding participants who would be willing to give up an hour or more of their vacation time is challenging.

Table 2 presents summary statistics of sample demographics and average bids by treatment. Household income was approximately $\$ 74,000$. This is relatively high for Delaware, which averages $\$ 58,000$ per year. However, it is important to keep in mind that the respondents were tourists who likely had higher than average incomes. In fact, the average household income observed in this study is only slightly above the broader mid-Atlantic region, as Maryland and New Jersey both have household incomes averaging \$70,000. Participants also tended to be older (mean 44.7) and had, on average, 16 years of education. The majority were on multi-day trips, and average spending on the vacation, across both day and overnight trips, was $\$ 1,563$.

Participants were recruited through open announcements, at a waiting area where pedestrian traffic lined up to board the ferry, and in an outside viewing deck after the ferry departed. The experiment took approximately 60 minutes, and the total possible earning was $\$ 45-\$ 20$ for participating, and an additional $\$ 25$ in bidding money to be used during the experiment.

Single sessions with groups of participants were run per ferry trip. The sessions took place in a cabin that had a small vending area and a large room full of tables and booths. This room was quiet and always had sufficient open space for participants to spread out, ensuring their privacy. Sessions consisted of low-stakes practice rounds which were done in a group, followed

Table 2. Summary Statistics

\begin{tabular}{lccr}
\hline & N & Mean & St Dev \\
\hline Bids for hotels & & & \\
$\quad$ Virden w/ turbine view & 65 & 4.88 & 6.14 \\
Virden w/o turbine view & 65 & 5.47 & 6.49 \\
Beacon w/ turbine view & 65 & 5.97 & 6.89 \\
Beacon w/o turbine view & 65 & 6.59 & 7.32 \\
Blue w/ turbine view & 65 & 8.92 & 8.14 \\
Blue w/o turbine view & 65 & 10.1 & 8.61 \\
Male & 61 & 0.53 & 0.50 \\
Age & 60 & 44.70 & 15.70 \\
Year of School & 59 & 16 & 2.85 \\
Household Income & 54 & 74,000 & 33,400 \\
Total Spending on Trip & 38 & 1,563 & 268 \\
Overnight Trip & 57 & 0.68 & 0.35 \\
\hline
\end{tabular}


by an individual high-stakes part. The low-stakes part familiarized participants with the BDM mechanism and the randomization procedures used in the experiment. Participants first bid on a pen. Next, they bid on two lottery tickets to win either a pencil or a pen. For each bid, participants received an initial endowment of one dollar. During the practice round, the low-stakes part of the experiment, participants bid on low-value items while sitting at a central table. Each participant was allowed to ask questions publicly of the administrators. For the low-stakes part, participants received a follow-up explanation and had the opportunity to ask questions. For the second, highstakes portion of the experiment, bidding on a weekend stay, participants were separated, seated at different tables to ensure privacy. Communication between participants was not allowed.

From the initial endowment of $\$ 23$ that participants received in the second part, they placed independent bids on lotteries for a weekend stay in six different hotel rooms. Participants could make a weekend reservation for the hotel any time in the following six months. The hotel rooms were identical except that arrangements had been made with the hotels so that one had a view of a 2-megawatt wind turbine, and the other did not. The hotels varied by quality and their distance from the wind turbine. Installed in 2010, the turbine is approximately 400 feet tall and 300 feet wide (diameter across rotors), and visible from all three hotels.

Participants were provided with the hotel's name along with its quality (star) rating and distance from the turbine. The Virden Center is a one-star hotel, located 0.23 miles from the turbine. The Beacon Motel is a one-star hotel, located 1.58 miles away. Hotel Blue is a three-star hotel, 1.53 miles away. ${ }^{1}$ Participants were provided with a table explaining the amenities associated with these ratings and examples of comparable chain hotels with which they were likely familiar. Each participant bid on rooms with and without turbine views for each hotel. To illustrate the visual scale of the turbine at these distances, participants were provided with a computer-generated graphic showing the turbine at each distance compared to a three-story office building (Figure 1). The participants were not given information on the hotels' rates, but for reference, a standard room in the Virden Center during the summer is typically $\$ 100$ per night, the Beacon is approximately $\$ 120$ per night, and Hotel Blue is around $\$ 250$ per night.

The graphic presented in Figure 1 was generated based on measurements of the existing wind turbine in Lewes, Delaware, scaled in a CAD program to ensure proper perspective. This visualization, while scaled accurately, certainly is limited in that it presented the view in an abstract setting instead

\footnotetext{
1 Because this field experiment involved choices for actual hotels, we were not able to test for impacts greater than 1.5 miles from the turbine, as no hotel in the area met that criterion. In the analysis, we pool the Beacon Hotel and Hotel Blue as being "far" from the turbine. While there is some difference in drive distance, the two adjoin the same parking lot, so the view is essentially identical.
} 


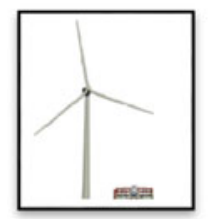

1.58 miles

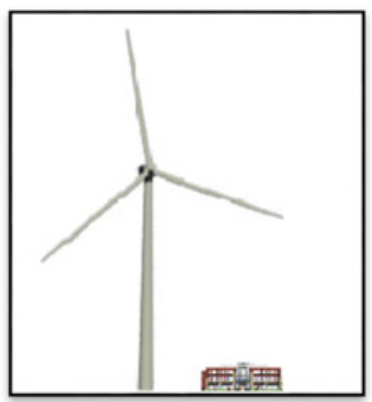

0.23 miles

\section{Figure 1. Images of a Turbine at Various Distances}

of in the context of an actual view from a hotel room. This was done because we wanted to experimentally isolate the impact of the turbine height and distance of the view. The reality was that the views from the hotel rooms differed by more than just the height and distance from the turbine. Other research has shown that the presentation format of visuals of turbines can influence participants' perception of them (see for instance Hevia-Koch and Ladenburg 2016). Because of this format, what is measured in this experiment can be interpreted as a tourist's expectation of the appearance of wind turbines before a hotel stay, as might influence decisions when booking, instead of the ex post value that one would have after staying in the hotel room.

Prices were randomly determined by dropping a marker onto a piece of paper with a grid of uniform random numbers between 0.01 and 23.00. If a participant's bid was above the determined price, he or she received the initial endowment minus the determined price and received the lottery ticket. If the bid was below the price, then he or she kept the initial endowment and did not receive the lottery ticket. Because only one randomly selected lottery ticket bid was binding, participants were encouraged to make each bid as if they had the full $\$ 23$ to bid on that ticket. For each selected ticket, the participant had a 1-in-10 chance of winning. If the participant had purchased the ticket, they would win the item if they rolled a seven on a ten-sided die.

Participants placed bids on all six hotel rooms simultaneously. To control for order effects, the order in which the rooms were listed was reversed for half of the participants. Even though participants placed bids on all six rooms, only one bid for a room was selected at random at the end of the experiment to determine the outcome and cash earnings. This procedure of selecting one random choice is common in experimental economics (Kotani, Messer, and Schulze 2008). To help participants understand how this random selection worked, the second parts of the practice section followed these procedures with the choice between a pencil and pen (see Appendix). 
After all bids were collected, the implemented hotel room choice and price were randomly determined. For those who purchased a lottery, they also rolled a die in private. If a seven was rolled, the participant won the weekend stay. All participants were paid privately to ensure all decisions made during the course of the study were confidential.

\section{Results}

Only three participants ( 4.6 percent) were familiar with of any of the three hotels. This ameliorates concerns about participants' pre-familiarity with the experiment items, which was particularly important because the image of the turbine was a key control used in this field experiment. ${ }^{2}$ Among the 65 participants, only 12.3 percent bid higher for hotel rooms with turbine views. On average, bids were significantly higher for the three-star hotel and significantly lower for rooms with turbine views. The lowest average WTP (\$4.88) was for the weekend stay at the Virden Center (one-star hotel) in a room with turbine views. The highest average WTP $(\$ 10.10)$ was at Hotel Blue (three-star hotel) in a room without turbine views.

Because the weekend stay was offered in a lottery, the magnitude of point estimates depends on assumptions about risk preferences. For example, if we assume risk neutrality, a bid of $\$ 10.10$ can be interpreted as a WTP of $\$ 101.00$ for a weekend at Hotel Blue without turbine views. If a participant is risk averse, $\$ 101.00$ captures the lower bound of the participants' WTP. The differential becomes larger when the curvature of the utility function, measuring risk aversion, increases. Average across rooms bids compare at $\$ 5-\$ 10$ for a 1:10 lottery, implying risk-neutral equivalents of $40-50$ percent of market value. This is not unreasonable, considering that the room stays were nontransferable and good only for a relatively limited time, and that the average included a fairly high number of zero bids.

Our main interest concerns how wind turbines affect tourists' preferences. Table 3 shows estimates of a model of participant $i$ 's bid as a function of the attributes of room $j$, being bid on:

$$
\begin{aligned}
\text { bid }_{i, j}= & \beta_{0}+\beta_{1} \text { Turbine }_{j}+\beta_{2} \text { Near }_{j}+\beta_{3} \text { ThreeStar }_{j}+\beta_{4} \text { Turbine } * \text { Near }_{j} \\
& +\beta_{5} \text { Turbine } * \text { ThreeStar }_{j}+\alpha_{i}+\varepsilon_{i, j}
\end{aligned}
$$

Here, turbine is a dummy variable with a value of 1 , if the hotel room being bid upon has a turbine view and 0 otherwise, Near has a value of 1 for the Virden Center and 0 otherwise, and ThreeStar has a value of 1 for Hotel Blue and 0

\footnotetext{
2 The analysis was conducted with and without these three participants, and the results were not substantially different. The results from the larger sample are presented here.
} 
Table 3. Coefficient Estimates of Tobit Estimate of Mean WTP.

\begin{tabular}{|c|c|c|c|c|c|c|c|c|c|c|}
\hline & Coef & P-Val & & Coef & P-Val & Coef & P-Val & & Coef & P-Val \\
\hline Turbine View & -1.31 & 0.001 & & -1.14 & 0.110 & -1.33 & 0.000 & & -1.15 & 0.008 \\
\hline Near & -1.72 & 0.001 & & -1.83 & 0.011 & -1.79 & 0.000 & & -1.84 & 0.005 \\
\hline Three Star & 5.04 & 0.000 & & 5.32 & 0.000 & 5.12 & 0.000 & & 5.43 & 0.000 \\
\hline Turbine*Near & & & & 0.13 & 0.897 & & & & 0.12 & 0.897 \\
\hline Turbine*Three Star & & & & -0.56 & 0.596 & & & & -0.62 & 0.495 \\
\hline Fixed Effects & & & No & & & & & Yes & & \\
\hline $\mathrm{N}$ & & & & & & & & & & \\
\hline Left Censored & & & & & & & & & & \\
\hline Right Censored & & & & & & & & & & \\
\hline
\end{tabular}


otherwise. The $\alpha$ term indicates subject-level effects. Because there were large numbers of bids of either $\$ 0$ or $\$ 23$, this was estimated as a Tobit model.

We estimate four variations on this model - two including the interaction terms, two omitting them, and two including fixed effects and two which omit them. Results across these models are quite consistent. Beach tourists have lower WTP at the 1-percent significance level for hotel rooms with turbine views or rooms that are closer to the turbines. Intuitively, tourists express a higher WTP for a three-star hotel than a one-star hotel. Additionally, all the interaction terms are found to be statistically insignificant; ${ }^{3}$ including them does make the estimate on the turbine view effect smaller and less significant. Assuming risk neutrality, this equates to an externality cost of around $\$ 18.40$ per visit for staying at the Virden Center, which was relatively closer to the turbine, and a cost of $\$ 11.50$ for having turbine views, regardless of location relative to the turbine.

\section{Conclusions}

This study, to our knowledge, is the first to use a within-subject field experiment to examine the visual externalities of wind turbines on tourism in a coastal community. The results suggest that tourists prefer a weekend stay in a hotel room without turbine views. These findings are consistent with the literature that wind turbines generate negative visual externalities to local beach communities (Ladenburg et al., 2005). While WTP differs by quality, the influences of turbine views on WTP does not.

Interestingly, 12.3 percent of the tourists had a higher WTP for hotel rooms with a turbine view even when the turbines were close $(0.23$ miles $)$, indicating that wind turbines could provide positive visual externalities to some tourists. This is consistent with the findings reported by Ladenburg and Lutzeyer (2012), who found three latent classes of preferences for wind farms located at two different differences, including totally positive, totally negative, and mixed based on distance. Although our sample size does not allow us to specifically analyze such behavior, it calls for future research to bring attention to studying this group of tourists' preferences.

\section{References}

Becker, G.M., M.H. DeGroot, and J. Marschak. 1964. "Measuring Utility by a Single-Response Sequential Method." Behavioral Science 9(3): 226-232.

Gee, K. 2010. "Offshore Wind Power Development as Affected By Seascape Values on the German North Sea Coast." Land Use Policy 27(2): 185-194.

3 Interestingly, of all demographic variables tested, only age has a significantly positive effect at the 1-percent level. Other demographic and attitude variables, including gender, education, income and environmental preferences are not significant at the 5-percent level. 
Gibbons, S. 2015. "Gone with the Wind: Valuing the Visual Impacts of Wind Turbines Through House Prices." Journal of Environmental Economics and Management 72: 177-196.

Krueger, A.D., G.R. Parsons, and J. Firestone. 2011. "Valuing the Visual Disamenity of Offshore Wind Projects at Varying Distances from the Shore." Land Economics 87(2): 268-283.

Kumar, Y., J. Ringenberg, S.S. Depuru, V.K. Devabhaktuni, J.W. Lee, E. Nikolaidis, B. Andersen, and A. Afjeh. 2016. "Wind Energy: Trends and Enabling Technologies" Renewable and Sustainable Energy Reviews 53(1): 209-224.

Ladenburg, J. 2009. "Stated Public Preferences for On-Land and Offshore Wind Power Generation: A Review." Wind Energy 12(2): 171-181.

- 2014. "Dynamic Properties of the Preferences for Renewable Energy Sources - A Wind Power Experience-Based Approach." Energy 76: 542-551.

Ladenburg, J., A. Dubgaard, L. Martinsen, and J. Tranberg. 2005. "Economic Valuation of the Visual Externalities of Off-Shore Wind Farms.” FOI Rapport; No. 179, Fødevareøkonomisk Institut, Copenhagen.

Ladenburg, J., and S. Lutzeyer. 2012. "The Economics of Visual Disamenity Reductions of Offshore Wind Farms-Review and Suggestions from an Emerging Field." Renewable and Sustainable Energy Reviews 16(9): 6793-6802.

Landry, C.E., T. Allen, T. Cherry, and J.C. Whitehead. 2012. "Wind Turbines and Coastal Recreation Demand." Resource and Energy Economics 34(1): 93-111.

Lang, C., J. Opaluch, and G. Sfinarolakis. 2014. "The Windy City: Property Value Impacts of Wind Turbines in an Urban Setting." Energy Economics 44: 413-421.

Lutzeyer, S., D.J. Phaneuf, and L.O. Taylor. 2016. "The Amenity Costs of Offshore Wind Farms: Evidence from a Choice Experiment." Working Paper.

Hau, E. 2005. Wind Turbines: Fundamentals, Technologies, Application, Economics. New Delhi, India: Springer-Verlag Berlin Heidelberg.

Heintzelman, M.D., and C.M. Tuttle. 2012. "Values in the Wind: A Hedonic Analysis of Wind Power Facilities." Land Economics 88: 571-588.

Hevia-Koch, J., and J. Ladenburg. 2016. "Estimating Preferences for Wind Turbine Locations A Critical Review of Visualization Approaches." USAEE Working Paper No. 16-278.

Parsons, G., J. Toussaint, E. Efimova, J. and Firestone. 2016. "The Impact of Offshore Wind Projects on Beach Recreation: A Contingent Behavior Study of Beach Use on the East Coast of the United States." University of Delaware Manuscript.

Poletti, P. 2005. "A Real Estate Study of the Proposed Forward Wind Energy Center Dodge and Fond du Lac Counties." Report prepared for Invenergy Wind LLC, Wisconsin.

Sterzinger, G., F. Beck, and D. Kostiuk. 2003. "The Effect of Wind Power Development on Local Property Values." Renewable Energy Policy Project: Washington DC, USA.

U.S. Department of Energy. "Advantages and Challenges of Wind Energy." http://energy.gov/ eere/wind/advantages-and-challenges-wind-energy. Retrieved Sept. 2015. 


\section{Appendix A: Instructions}

\section{Zebra Z-Grip Ball Point Pen}
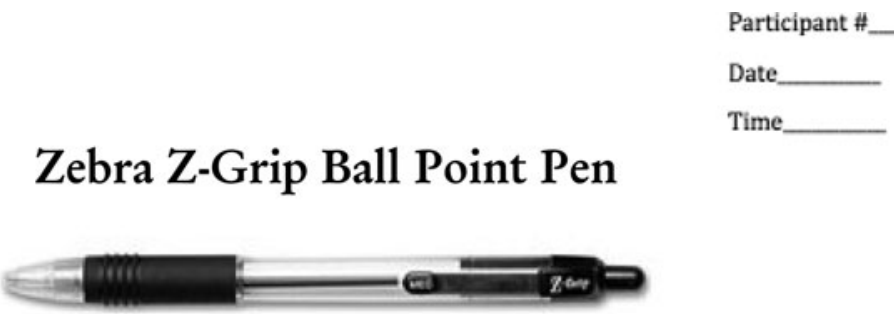

In today's experiment, you will be asked to indicate the highest amount of money you would pay for different items. We will refer to this amount as your bid. The first item is a Zebra Z-Grip Ball Point Pen.

This part of the experiment will proceed as follows:

1. First, we will give you $\$ 1.00$.

2. Next, you will submit a bid for this pen. This bid should be the highest amount of money that you would pay for this pen. Your bid can be any amount between $\$ 0.00$ and $\$ 1.00$.

3. After you have submitted your bid, the price of the pen will be determined using a random numbers table, such that the price will range from $\$ 0.00$ to $\$ 0.99$, where each number is equally likely. This price will be determined by having you drop a marker onto a random numbers table as will be demonstrated by the administrator.

4. One you submit your bid and the price is determined, there are two possible outcomes:

You PURCHASE the pen. This happens when your bid is greater than or equal to the randomly determined price. In this case, you will purchase the pen and receive the remaining balance from your $\$ 1$ after the price has been paid.

You DO NOT PURCHASE the pen: This happens when your bid is less than the randomly determined price. In this case, you will not receive the pen nor pay the price, but instead receive the entire initial balance of $\$ 1$.

Note that it is in your best interest to submit a bid equal to the maximum amount of money you would be willing to pay for this item, since if you purchase the pen, you will only have to pay the randomly determined price, not the amount of your bid. 


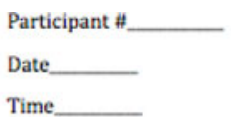

\section{Ticket for Zebra Z-Grip Ball Point Pen or Ticonderoga Pencil}

The procedures in this part are similar to the ones used in the last part. Again you will receive $\$ 1.00$ and the price will again be determined randomly from a range of $\$ 0.00$ to $\$ 0.99$. However, in this part there are two important differences:

1) In this example you will be bidding on tickets for two different writing instruments, a Zebra Z-Grip Ball Point Pen or a Ticonderoga Pencil. For each writing instrument, you will be deciding how much to bid for a ticket for a chance to win a writing instrument. A ticket has a one-inten chance of winning.

2) Only one of these items will be sold. This will be determined by having a volunteer flip a coin. If the coin shows "heads" the pen will be the item for sale, if the coin shows "tails" the pencil will be the item for sale.

There are two possible outcomes:

You PURCHASE the ticket: The ticket is purchased if your bid is greater than or equal to the price. In this case, you will receive the ticket with a onein-ten chance of winning the writing instrument in addition to the remaining balance from your $\$ 1$ after the price has been paid. If you purchase a ticket, you will then roll a ten-sided dice once and if you roll the number " 7 " then you will win the pen.

You do NOT PURCHASE the ticket: The ticket is not purchased if your bid is less than the price. In this case, you will not receive the ticket, but you will not have to pay the price. Therefore, your cash earnings for this part would be $\$ 1$. 


\section{Ticket for Hotel Room in Lewes, Delaware}

Participant \#

Date

Time,

The procedures for this part are similar to the ones used in the last section, except for four important differences.

1) Your initial balance is $\$ 23$.

2) The randomly determined price will be between $\$ 0.00$ and $\$ 22.99$.

3) The purchase decision is for a ticket that has a one-in-ten chance of earning you a free weekend (Friday and Saturday night) stay at a hotel in Lewes, Delaware, any weekend during the hotel's offseason, which generally runs from September to

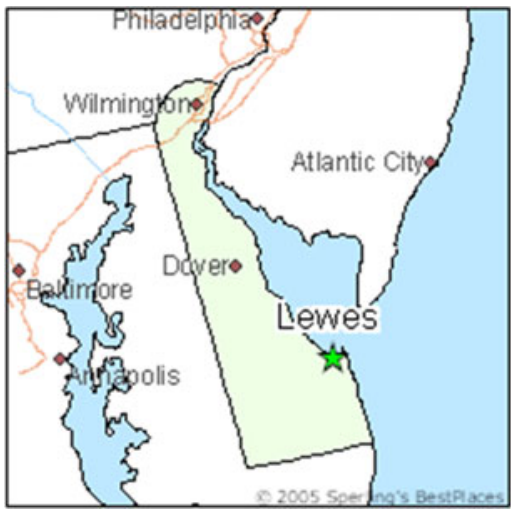
May.

4) You will place a bid for six different tickets (\#1-6). Two tickets each from one of three hotels. The rooms at a particular hotel will be identical, except that one will have a view of a wind turbine.

One of these six tickets will be sold. Which one is sold will be determined at the end of the experiment by having a volunteer roll a six-sided die. Because you do not know which of the six tickets will be sold, you should consider each choice independently in the event that the choice is chosen.

The two possible outcomes in this case will be:

The ticket is PURCHASED: The ticket is purchased if your bid is greater than or equal to the price. In this case, you will receive the ticket with a onein-ten chance of winning a weekend stay at a hotel in Lewes, Delaware, in addition to the remaining balance from your $\$ 23$ after the price has been paid. If you purchase the ticket, you will then roll a ten-sided dice once and if you roll the number " 7 " then you will win the ticket.

The ticket is NOT PURCHASED: The ticket is not purchased if your bid is less than the price. In this case, you will not receive the ticket, but you will not have to pay the price. Therefore, your cash earnings for this part would be $\$ 23$.

The hotel rooms that you will bid on are from three different hotels: the Virden Center, the Beacon Motel, and the Hotel Blue. These hotels have star 
ratings based on amenities, as described by the following standard one to five star scale.

$\checkmark$ (One Star) - appeals to the budget-minded traveler. They provide essential, no-frills accommodations and basic comfort and hospitality. Motel 6 and Super 8 are typical one star hotels.

(Two Stars) - appeals to travelers seeking affordable yet more than the basic accommodations. Facilities, decor and amenities are modestly enhanced. Best Western and Holiday Inn are typical two star hotels.

(Three Stars) - offer a distinguished style. Properties are multi-faceted, with marked upgrades in physical attributes, amenities and guest comforts. Courtyard by Marriott and Hilton Doubletree are typical three star hotels.

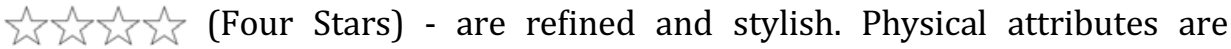
upscale. The fundamental hallmarks at this level include an extensive array of amenities combined with a high degree of hospitality, service and attention to detail. Hyatt Regency and Hilton Resorts are typical four-star hotels.

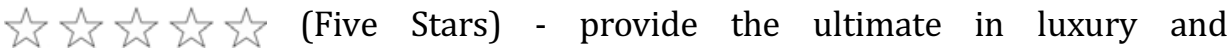
sophistication. Physical attributes are extraordinary in every manner. Service is meticulous, exceeding guest expectations and maintaining impeccable standards of excellence. Extensive personalized services and amenities provide first-class comfort. Ritz-Carlton and Hilton Resorts are typical fourstar hotels.

The following page has information about each hotel including the star rating, distance from the turbine, and the approximate appearance of that height at the given distance, as compared to a three-story office building. Consider each hotel one at a time and place your bids for the rooms.

\section{Please Stop Here}




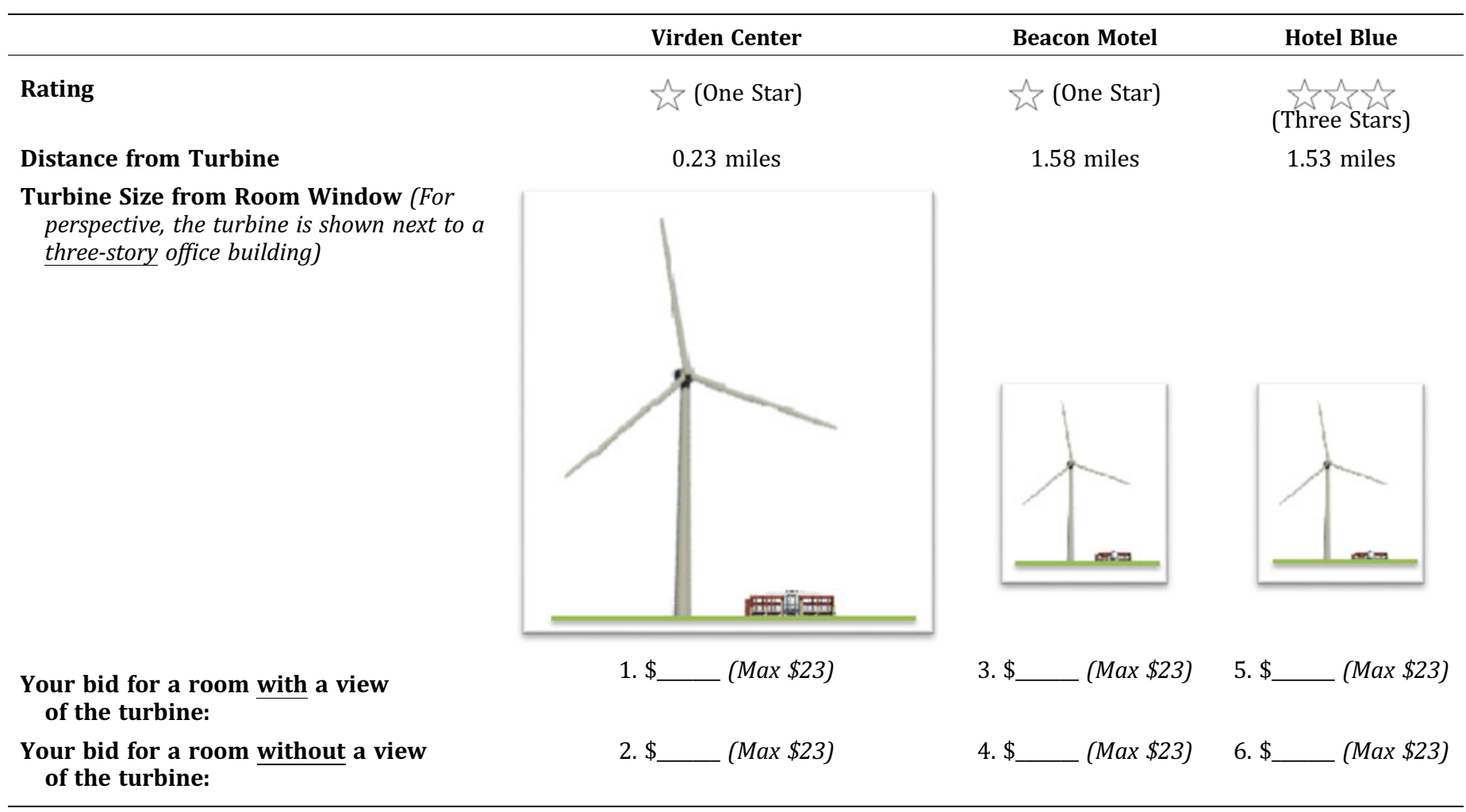


Participant \#

Date

Time

\section{Survey on the Public's Perceptions of Wind Turbines}

Please answer the following questions. Your responses will be kept confidential. Please do not put your name on any of the materials. Any questions may be addressed to the study administrator.

1. Please indicate your sex.

$\mathrm{M} \longrightarrow \mathrm{F}$

2. In what year were you born?

3. In what zip code is your primary residence located?

4. How would you describe your area of residence?

_Urban _ Rural __ Suburban

5. How many years of formal schooling have you completed (High school diploma $=12$ years)?

6. Are you currently...?

__ Employed Full Time ___ Employed Part Time Self Employed

Student Homemaker Retired

__ Unemployed

7. What is your total household gross annual income?

\begin{tabular}{|c|c|c|}
\hline Less than $\$ 20,000$ & $\$ 140,001-\$ 160,000$ & $\$ 280,001-\$ 300,000$ \\
\hline$\$ 20,001-\$ 40,000$ & $\$ 160,001-\$ 180,000$ & $\$ 300,001-\$ 320,000$ \\
\hline$\$ 40,001-\$ 60,000$ & $\$ 180,001-\$ 200,000$ & $\$ 320,001-\$ 340,000$ \\
\hline$\$ 60,001-\$ 80,000$ & $\$ 200,001-\$ 220,000$ & $\$ 340,001-\$ 360,000$ \\
\hline$\$ 80,001-\$ 100,000$ & $\$ 220,001-\$ 240,000$ & $\$ 360,001-\$ 380,000$ \\
\hline$\$ 100,001-\$ 120,000$ & $\$ 240,001-\$ 260,000$ & Greater than $\$ 380,000$ \\
\hline$\$ 120,001-\$ 140,000$ & $\$ 260,001-\$ 280,000$ & Prefer not to say \\
\hline
\end{tabular}


8. Do you own property in a Delaware beach community (within 5 miles of an ocean beach)? (Exclude investment properties)

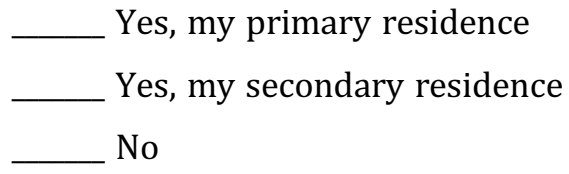

9. Are you staying in the Delaware beach area for more than one night on your current trip? (Please skip if your primary residence in a Delaware beach community)

$$
\text { Yes No }
$$

-If yes, for how many nights are you staying?

10. Including yourself, how many people are you traveling with?

- How many children under 18 ?

11. How many days have you been to Delaware's ocean beach areas since Memorial Day

(May $\left.28^{\text {th }}\right)$ ?

12. How many more days do you expect to go to Delaware's ocean beach areas before Labor Day

(Sept. $\left.3^{\text {th }}\right)$ ?

13. Are these primarily day trips or overnight trips? Day Overnight

14. How many years have you been coming to Delaware's ocean beach area?

15. Have you ever stayed at the :

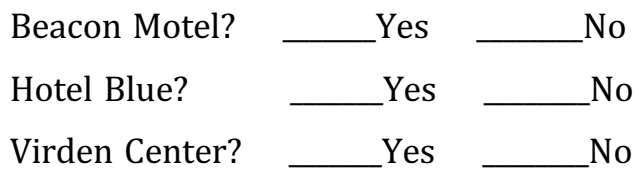


16. Have you ever been inside the:

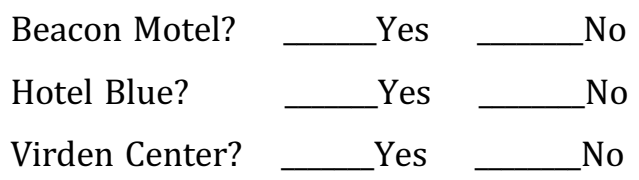

17. Do you know where the ... is located?

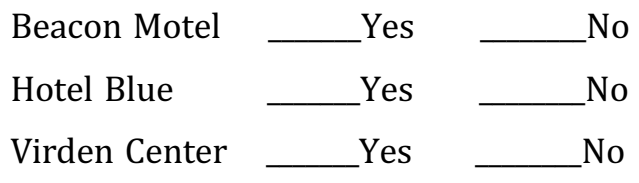

18. On a 1 to 9 scale how would you rate the quality of the following hotels Beacon Motel

Very Low

$\begin{array}{llll}1 & 2 & 3 & 4\end{array}$

Hotel Blue

Very Low

Average

$\begin{array}{lllll}5 & 6 & 7 & 8 & 9\end{array}$

Don't Know

Virden Center

Very Low

Average

$\begin{array}{llll}1 & 2 & 3 & 4\end{array}$

$\begin{array}{lll}5 & 6 & 7\end{array}$
Very High

89

Don't Know 